\title{
The Cuckoo's Nest Approach for Co-Creating Business Ecosystems in Smart Cities
}

\author{
Karlos Artto, Riikka Kyrö, Tuomas Ahola, \\ Antti Peltokorpi, and Kristiina Sandqvist
}

\author{
"The stars up close to the moon were pale; they" \\ got brighter and braver the farther they got out \\ of the circle of light ruled by the giant moon.
}

Ken Kesey (1935-2001)

In One Flew Over the Cuckoo's Nest (1962)

\begin{abstract}
The development of business ecosystems in smart cities is currently hampered by the absence of established approaches for facilitating long-term value and sustainability. In our view, the underlying reason is the lack of collective action involving various organizations in the design process. Collective action for the good of the whole ecosystem does not take place in existing participatory practices because of the dominating role of a single customer or designer organization (in urban development projects typically the owner-developer or lead architect), who uses their bargaining and decision-making power over others. This leads to sub-optimal behaviour where the system is optimized for the goals of one strong organization instead of collectively developed system-level goals of the business ecosystem as a whole. The Cuckoo's Nest approach addresses this problem by inviting various expert organizations to design the system and assigning each organization design rights for the ecosystem and its system-level goal. The Cuckoo's Nest approach enhances collective action among the organizations by making individuals from various organizations consider the interests, goals, objectives, and value-adding elements of other organizations - not just those of their own organizations. With the Cuckoo's Nest approach, the business ecosystem comes first, and single organizations' goals or specific design features come second. This article discusses the outcomes of two workshops where the Cuckoo's Nest approach was used for the purpose of developing business ecosystems in connection with smart city development projects within the Helsinki Metropolitan Area. We outline the steps involved in the Cuckoo's Nest approach and how they were applied in these two smart city projects, and we describe how it is being refined for further use in other locations and contexts.
\end{abstract}

\section{Introduction}

The current global megatrends of rapid urbanization and digitalization are placing great pressure on the sustainability of our cities and are bringing about major changes in the living environment of city dwellers. Simultaneously, these trends also offer increased possibilities for sustainable urban development following the principles of circular economy, including the exploitation of existing infrastructure and services while taking advantage of new technology. Additionally, smart city strategies include engaging citizens and local businesses in the development of their communities. Indeed, participatory planning has been a growing trend in urban development projects in the past few decades. End users have been increasingly engaged in design processes using different collaborative methods. While this is a clear improvement compared to a designercentric approach, the existing participatory planning methods generally involve a pre-defined object of design, as well as a professional designer to lead the process. 


\title{
The Cuckoo's Nest Approach for Co-Creating Business Ecosystems in Smart Cities
}

\author{
Karlos Artto, Riikka Kyrö, Tuomas Ahola, Antti Peltokorpi, and Kristiina Sandqvist
}

This article stems from the premise that, despite advancements in end-user and community participation, planning practice has continued to put the designerarchitect in the leading role and to identify the physical environment as the ultimate goal of the process. Modern solutions, such as the cave automatic virtual environment (CAVE; tinyurl.com/pcraeq7) and living labs, allow for users to experience the facility that is being designed but therefore also inherently impose the facility design on the user. In an attempt to shake this tradition, Aalto University's Project Business Research Group developed a novel approach to collaborative design: the Cuckoo's Nest approach. The focus of this new approach is on business ecosystem development, and it gives individuals the freedom and independence to use all their previous personal or business expertise in the process.

The Cuckoo's Nest approach focuses on developing a business ecosystem and its system-level goal through collective action. With this process, we invite individuals representing different professions and fields of business to collectively create a multi-organizational network. Invitations are extended to all organizations related to the ecosystem under design, not only the known developers and designers or intended users. The Cuckoo's Nest design process builds on the services and processes that the organizations are willing to develop in collaboration with others. The process steers the organizations towards seeing the "bigger picture" and the business ecosystem as a whole, rather than suboptimizing and promoting their own individual businesses. This principle is supported by the theories of business networks, which suggest that: i) networks are dependent on the different resources possessed by their organizations (Hakanen \& Jaakkola, 2012), ii) that relationships between organizations can be characterized by their competing or complementing offerings (Casadesus-Masanell \& Ricart, 2011), and iii) that network development is a purposeful activity coordinated by a focal firm (Ritala et al., 2012).

The context of the current study is smart city development, and it explores two case projects where the Cuckoo's Nest approach and associated workshop method was used to design business ecosystems (Autio \& Thomas, 2014). Both case workshops focused on smart city development projects within Finland's Helsinki Metropolitan Area: i) the Otaniemi Metro Centre and ii) the Ruskeasuo Health Park. The ecosystem for the Otaniemi Metro Centre focuses on a planned facility to be built on a campus of Aalto University. The
Ruskeasuo Health Park's ecosystem focuses on a hospital campus. During the associated case workshops for each case, real estate developers and architects participate in the workshop as peers, not as facilitators or in other pre-established roles. The same principle also applied to larger retail chains, which often dominate retail development projects. During the Cuckoo's Nest workshops, smaller retailers and other small organizations had equal weight in contributing to the design of the business ecosystem.

These two cases represent an application and refinement of the Cuckoo's Next approach. This article introduces the study (and the new approach) by first providing background on existing participatory approaches. Then, the study design, including the case descriptions and the workshop process is described. Next, the outcomes of the two workshops are analyzed. Finally, we offer conclusions and look ahead to the future of the two cases and the application of the Cuckoo's Nest approach to new contexts and locations.

\section{Background: Existing Participatory Approaches}

Participatory planning is a form of co-design and has been well represented in urban development projects for at least two decades. End users have been engaged in city planning processes using different participatory methods, such as workshops, discussion forums, and interviews. Engaging in dialogue with the community is generally considered good practice and professionalism on behalf of the planner (Forester, 1999). Consequently, different participatory methods have also been introduced in planning school curricula. Booher and Inner (2002) argue that planners need to have management, facilitation, mediation, and negotiation skills. Participatory planning methods have been developed for and used in different built environment projects, whether an individual building or an urban neighbourhood (Sanoff, 2000). In Finland, the location of the current study, urban planning has become significantly more community focused in recent years, and participatory methods are widely used (Horelli, 2013).

End user experiences have been particularly well accommodated in the design of healthcare environments (e.g., Bowen et al., 2013; Carmel-Gilfilen \& Portillo, 2016; Elf et al., 2016; Luck, 2003; Perkins, 2013) and modern learning environments (e.g., Brown \& Long, 2006; Kyrö \& Artto, 2015; Kyrö et al., 2016; Rytkönen, 2015). Bowen and colleagues (2013) introduce a case of experiencebased design from the healthcare sector, which utilized 


\section{The Cuckoo's Nest Approach for Co-Creating Business Ecosystems in Smart Cities} Karlos Artto, Riikka Kyrö, Tuomas Ahola, Antti Peltokorpi, and Kristiina Sandqvist

the method of storytelling. Similarly, in healthcare, a group of design students found that user stories enhanced their empathy and thus made for a better design (Carmel-Gilfilen \& Portillo, 2016). Regarding the focus on designing the business that takes place in the facility (and not designing the facility as being separated from the actual business ecosystem), Elf and colleagues (2016) introduce a method called group modelling, where workshops are used for the primary purpose of the development of the healthcare organization and processes; the plans of the facility are then prepared only after the organization and processes have been designed properly in the group modelling exercise.

Meanwhile, Redström (2006) finds the whole concept of participatory design problematic, because the perceived end user does not exist until a designer creates something for them to use. His argument is that the perceived user cannot know how they will experience the designed object once it is finalized, therefore design should be left solely in the hands of the architect or professional designer. With the help of modern design tools, such as virtual environments, his argument seems philosophical at best, invalid at worst. Sanders and Stappers (2008) argue that, in recent years, the user has actually been promoted from an object of the design (user-centered design) to a co-designer, however, the designer still has a key role in giving form to the design. They also point out how co-design challenges existing power structures, which may be difficult for those who are used to being in charge of the design process. Luck (2003) considers that the difference between user and designer is sometimes blurred due to the major role given to end users. Horelli (2013) goes even further and suggests that participatory approaches should move towards self-organized participation instead of top-down, staged participation.

The various participatory approaches are used for collectively defining the system (e.g., a project, its outcome, or the ecosystem), and therefore collective action is at the core of such approaches. Broader theorizing on collective action can be found in Ostrom (1990) and Olson (1965). To facilitate the collective action to leverage knowledge integration and networked innovation, selecting appropriate boundary objects are of importance (Mäenpää et al., 2016). To enhance knowledge integration and innovation, the aim of boundary objects should be to even out the power structures and achieve a common understanding between the various actors, and to allow for putting focus on the business ecosystem design and not merely the facility design. Kjolle and Blakstad (2014) used a boundary object in the form of a design brief to enhance collaboration and innovation among actors participating to a workshop. For workplace design, Broberg, Andersen, and Seim (2011) list several possible boundary objects, including layouts, usability tests, focus group interviews, to-scale or full-size mockups, computer visualization, and slideshows, as well as the activities of testing and visiting other workplaces. Participatory approaches are also linked to the principles of open innovation, where both internal and external actors are included in the innovation process (Chesbrough, 2003). Furthermore, Chesbrough (2007) argues that setting up relationships with different organizations such as suppliers, competitors, complementors, research institutes, and end customers is crucial for scalable, practical, and effective innovation. Additionally, in line with the service-dominant logic, innovation development should always be targeted at a customer need (Vargo \& Lusch, 2004).

\section{Study Design}

In this section, we outline the overall design of our study and introduce the two cases before detailing the new Cuckoo's Nest approach, which is designed to overcome the shortcomings of existing participatory approaches, as described in the previous section. The research was conducted as action research with observation as the main data collection method. Data was collected from two workshop sessions, where the research team participated as facilitators. All workshop discussions were also recorded and transcribed for research use. The study is qualitative and exploratory, and it focuses on two different campus development projects. Selecting two cases for the workshops gave a better indication of how the Cuckoo's Nest approach can be applied and how the results may vary in different contexts. The following subsections introduce the context and basic characteristics of the two cases and workshops.

\section{Case 1: Otaniemi Metro Centre}

The first case for the Cuckoo's Nest was a future shopping centre located on the Aalto University campus in Otaniemi, Espoo. Aalto University is the leading university of technology, business, and arts in Finland. Most existing buildings on campus date back to the 1950-60s and were designed by the renowned Alvar Aalto, after whom the university is now named. The campus attracts architecture enthusiasts from around the world, in addition to students, faculty, and visitors to the university. The shopping centre will be de- 


\section{The Cuckoo's Nest Approach for Co-Creating Business Ecosystems in Smart Cities}

Karlos Artto, Riikka Kyrö, Tuomas Ahola, Antti Peltokorpi, and Kristiina Sandqvist

veloped in connection with a new university building and a metro station. The new metro line of the city of Espoo will have several new stations, and new shopping centres are planned at almost every station. It was therefore seen as crucial for the Aalto University station shopping centre to be unique and attractive enough to compete with other new shopping centres in nearby stations.

Local businesses were invited to join the workshop. It was decided that the focus would be on retail chains that would have experience in operating in a shopping centre setting. Preliminary discussions were held with 40 people, of whom 20 agreed to participate and eventually 17 , representing the public (2) and private (15) sectors, were present in the workshop. The owner-developer of the shopping centre was also present, however, the research team was solely responsible for the organizing the workshop and sending invitations to the organizations. The workshop was held on March 13,2015 , in a newly developed social learning environment on the university campus. The place was purposefully selected because it allows for group working and offers relaxed surroundings. The participants were divided into three groups so that the groups were as diverse as possible, representing different fields of business, profession, gender, and age (Table 1).

In addition to the facilitators for the overall workshop, each group had a separate facilitator and a secretary who focused on taking field notes and pictures. Altogether, eight researchers from the research team were present at the workshop.

\section{Case 2: Ruskeasuo Health Park}

The second campus development project was initiated when the owner of a hospital campus signified interest in improving the vacancy rates on campus and energizing the campus with new activity. The campus hosts a rehabilitation hospital and a few smaller organizations, such as retailers of assistive devices. The hospital campus has a long history, dating back to the 1940s, when injured veterans returning from the war needed to be treated and rehabilitated in Helsinki. The campus is located centrally in the Ruskeasuo area of Helsinki, with great recreational opportunities due to the nearby Central Park. Currently, senior citizens represent the main customer segment, and the owner wishes to develop the campus into a full-service "wellbeing campus" with a wide range of offerings from the health and wellbeing industry. The workshop, therefore, focused on finding the right type of service compilation for the new campus.
Table 1. Cuckoo's Nest workshop participants for the Otaniemi Metro Centre

\begin{tabular}{lll}
\hline Group & Participant's Field of Business & Sector \\
\hline Group 1 & Grocery retail (large scale) & Private \\
& Clothing retail & Private \\
& Clothing retail & Private \\
& Private planning agency & Private \\
& Espoo city planning agency & Public \\
\hline Group 2 & Grocery retail (large scale) & Private \\
& Pharmacy & Private \\
& Hardware and gardening retail & Private \\
& Restaurant & Private \\
& Real estate developer & Private \\
& Owner/developer & Private \\
\hline Group 3 & Finnish Post & Public \\
& & (state owned) \\
& Movie theater & Private \\
& Restaurant & Private \\
& Liquor retail & Private \\
& & Private \\
\hline
\end{tabular}

For this workshop, the researchers invited many public and third sector organizations to participate in the workshop, because these sectors are active in the health and wellbeing industry. The owner also participated in the workshop, but not in a leading role. Invitations were sent to 21 individuals, and 13 participants representing the public (4), private (3), and third (6) sectors took part in the workshop on June 5,2015 . It was decided that the workshop would be held on the campus, and the most suitable place was a large meeting room in the hospital. The participants were again divided into three groups so that each group would have a diverse set of individuals (Table 2). 


\section{The Cuckoo's Nest Approach for Co-Creating Business Ecosystems in Smart Cities}

Karlos Artto, Riikka Kyrö, Tuomas Ahola, Antti Peltokorpi, and Kristiina Sandqvist

In addition to the facilitators for the overall workshop, each group had a separate facilitator and a secretary who focused on taking field notes and pictures. Altogether, seven researchers from the research team were present at the workshop.

\section{The Cuckoo's Nest Approach}

The Cuckoo's Nest approach takes its name from Ken Kesey's (1962) novel One Flew Over the Cuckoo's Nest, and it highlights an entrepreneurial focus that encourages all individuals to think freely and differently from others. Just like the patients in Ken Kesey's book, who sought to advance the good for everyone, our workshop participants are encouraged to consider the ecosystem as a whole. Furthermore, like in the Cuckoo's Nest approach, the thinking of individuals should not be constrained by the ideas of single strong organization such as the designer or developer - or "the giant moon" referenced in the opening quotation to this article - using its power to draw the attention of others for the advancement of this one strong organization's goals only.

This section introduces the final form of the workshop method for the Cuckoo's Nest approach, which was developed further from its original form based on the experiences from the first workshop. The workshop format includes five consecutive phases as illustrated in Figure 1 and described below:

1. Memory Lane: The workshop is initiated with all participants in one group, and everyone is asked to recall and share a positive personal memory related to the theme of the workshop. This exercise is meant to create inclusiveness and prime the participants to the workshop and upcoming tasks. It also functions as an introduction. After this first phase, the participants are divided into groups. The number of groups and group size can be adjusted depending on the context. Based on our experience from the two Cuckoo's Nest workshops described here, we suggest that a group size of four to six individuals can enhance appropriate variation in results while still integrating knowledge for innovative ecosystem design among the group members. Regarding the number of groups, we see that the number can potentially be constrained by the availability of facilitators and secretaries assigned to each group separately, and the available workshop space.

2. Actor Domino: The second phase of the workshop creates the ecosystem design by suggesting an appropriate business and service mix. Each group is given
Table 2. Cuckoo's Nest workshop participants for the Ruskeasuo Health Park

\begin{tabular}{lll}
\hline Group & Participant's Field of Business & Sector \\
\hline Group 1 & Private planning agency & Private \\
& City of Helsinki healthcare unit & Public \\
& Secondary Education provider & Public \\
& Association for osteoporosis & Third \\
\hline Group 2 & Diabetes association & Third \\
& Association for people with disabilities & Third \\
& Local school administration & Public \\
& Wellbeing association & Third \\
& Real estate owner/developer & Private \\
\hline Group 3 & Health association & Third \\
& City of Helsinki planning department & Public \\
& Local Lutheran congregation & Third \\
& Real estate owner/developer & Private \\
\hline
\end{tabular}

a pack of "actor cards" from which they can select the best business ecosystem compilation by suggesting a set of business actors that would make an appropriate whole (as an ecosystem). The cards are of different colour based on the business sector (e.g., café, restaurant, grocery store, clothing store, hardware, recreation, or services provided by banks or libraries). Some of the cards include specific brand names; some only indicate the sector. The task is first done individually and participants are not allowed to choose their own businesses in the mix. This task forces participants to compromise and to think about the good of the whole business ecosystem, not just their own organizations. Following the individual task, the Actor Domino process is restarted, but this time as a group activity. The groups are asked to combine the best suggestions from each individual to come up with a new unique set of business ecosystem constituents.

3. Doll House: The third phase of the workshop is the only phase that focuses on the layout of the ecosystem in relation to space. The name Doll House refers 


\title{
The Cuckoo's Nest Approach for Co-Creating Business Ecosystems in Smart Cities
}

\author{
Karlos Artto, Riikka Kyrö, Tuomas Ahola, Antti Peltokorpi, and Kristiina Sandqvist
}

to a miniature house that is modelled and decorated according to a child's or family's own liking. The rooms can be of different size and be located in different parts of the house. For this assignment, the participants are provided with a toolkit including miniature figures, wall partitions, cardboard, and tape. The number and placement of buildings, the number of floors, the choice of building materials, as well the location of the different business facilities are decided within the group. Given that the ecosystem in terms of its business and service compilation has been designed already (in the previous phase), the codesign process innately becomes activity-based. The name Doll House refers to a physical space, but this phase is not necessarily constrained by a requirement to position the ecosystem in a specific location (because the idea is to design the location and space without unnecessary constraints). Therefore, if the business ecosystem designed in the workshop is virtual, we suggest that the Doll House phase includes a positioning of the ecosystem as based on the mutual relationships and connections of its members by other parameters than the physical location only.

4. Loyalty Card: The fourth phase of the workshop is inspired by the many loyalty programs initiated by retail chains that seek to reward loyal customers and promote brand identity. Each participant is invited to suggest a name and a slogan for the ecosystem based on the outputs of the previous phases, and earlier discussions with the group. The group then decides upon their joint suggestion for name and slogan that would appear on the hypothetical loyalty card for the ecosystem. This simple task plays an important role in determining the identity for the business ecosystem, which would represent an integrative force for the existence and purpose of the ecosystem by the ecosystem members.

5. Speaker's Corner: In this phase, each participating individual is asked to think about their own personal views about the idealized ecosystem that the individual wishes to see in the future. Based on this individual and idealized view, each individual is asked to step to a spot called the Speakers' Corner and give a three-minute speech to others on the theme of "my ecosystem" to describe the kind of ecosystem that, in their mind, constitutes the perfect business ecosystem, and would bring them joy. The idea behind this Speakers' Corner phase is to allow for individuals to establish a personal connection to the ecosystem of "their own", and also to share different views and opinions, and also expose and encourage variation among the participants' opinions.

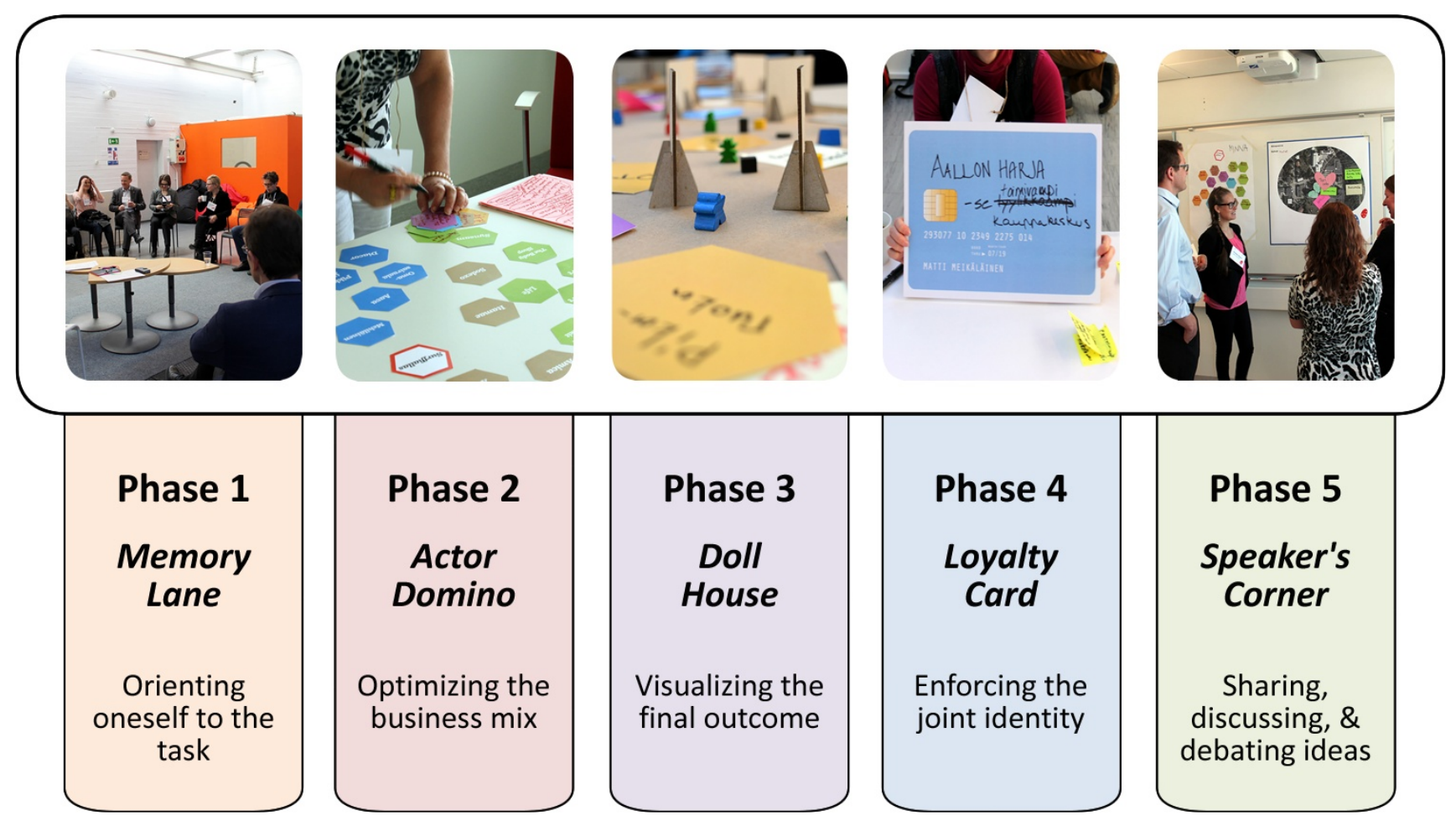

Figure 1. The five phases of Cuckoo's Nest workshop 


\section{The Cuckoo's Nest Approach for Co-Creating Business Ecosystems in Smart Cities} Karlos Artto, Riikka Kyrö, Tuomas Ahola, Antti Peltokorpi, and Kristiina Sandqvist

During the entire workshop, the participants are reminded that they are not restricted by any existing physical, economic, or emotional constraints. The logic is that the sense of freedom will produce a range of "outside-the-box", altruistic ideas. The feasibility of the suggestions is not assessed at all in the workshops.

\section{Findings}

In this section, we present the key outcomes of the two case workshops. The findings are based on the extensive written and photographic documentation that was collected by the researchers during the workshops, as well as the outputs created during the workshops (Actor Domino compilations, Doll House layouts, and Loyalty Cards).

The two workshops were conducted similarly but with minor differences. First, the locations for the workshops were different, even though both were located on the respective campuses. The setting on the university campus was a modern social-learning environment whereas the other workshop was held in a more traditional meeting room. However, the atmosphere in both workshops was relaxed. Particularly for the Health Park workshop, the opening phase of Memory Lane - where participants were asked to recall a positive experience related to healthcare - clearly helped create a sense of trust among all participants.

Second, some modifications were made in the latter workshop based on experiences in the first workshop. During the first workshop, the research team noticed that the Speaker's Corner - where individuals were asked to present their own idea of an ideal shopping centre - drew the participants "back to reality" in an unfortunate way. Despite very innovative and even radical outputs from the first phases of the workshop, the individual speeches comprised rather traditional shopping centre compositions. In a way, the participants started to question the feasibility of their own ideas and started to speak on behalf of the organizations they represented. This phase was therefore changed for the second workshop so, that the facilitators presented the ideas created by the group. However, this modification resulted in a bleak, less exuberant atmosphere. For good or bad, the Speaker's Corner phase utilized in the first workshop forced the participants to step out of their comfort zone. Despite the minor, brief uneasiness for the participating individuals, the Speaker's Corner phase should remain an integral part of the Cuckoo's Nest approach in the future.
Furthermore, the Doll House phase did not produce any radical or even very detailed layouts during the first workshop, and the groups spend much more time pondering on the identity of the shopping centre. Therefore, the phase was changed in the second workshop so that the participants were not asked to come up with building layouts but rather focus on the activities on the campus. Interestingly, however, the groups did actually come up with a rather detailed layout for the campus anyway. For future workshops, the Doll House phase will be introduced so that the groups are provided with the basic design toolkit, as described in the previous section. This way, the groups may themselves decide how detailed their layout design will be.

Below, we share specific findings of the two case workshops.

\section{Otaniemi Metro Centre}

The shopping centre will be developed in connection with a university building and the metro station. These two prerequisites were the only ones given to the participants. No restrictions on the facilities, number of tenants, purpose of use, or other characteristics of the shopping centre were given in advance.

The participants wished to see the Otaniemi Metro Centre as very tech savvy and boast an ecological conscience. A consensus was reached on the importance of the building design, including façade and materials, in depicting the ecosystem identity. The participants actively discussed the salient features of the ecosystem, starting from the beginning of the workshop when justifying their choices for Actor Domino, and throughout the Doll House phase when deciding the layout. As a result, the identity of the shopping centre, and how it would be created, became a key topic. The campus surroundings and the university community had a major impact on the identity.

Many participants drew from their own unique shopping experiences abroad and were, therefore, contemplating what Otaniemi campus and Finland as a country could offer that other countries could not. Nature on the one hand and technological advancements on the other were discussed as potential niche attractions. Interestingly, a traditional shopping centre in terms of layout and service compilation was not preferred by anyone, even though everyone admitted to visiting shopping centres for the ease of finding everything under one roof. However, the new shopping centre should be a contemporary version of a traditional village that highlights the tech-savvy identity of the university campus. 


\section{The Cuckoo's Nest Approach for Co-Creating Business Ecosystems in Smart Cities} Karlos Artto, Riikka Kyrö, Tuomas Ahola, Antti Peltokorpi, and Kristiina Sandqvist

The participants' suggestions also strongly reflected their own experiences and needs as consumers. Few participants saw themselves as the target group for shopping centres, and shopping centres in general were thought to have a slightly outdated feel, even a stigma. As a result, many novel and innovative suggestions could be found in the outputs of the workshops. Instead of traditional shops, the shopping centre would include pop-up stores and showrooms. Traditional shops in the future might just become places for testing a product before ordering it and having it delivered directly to your home. The suggestions reflect the megatrends of urbanization and digitalization, which are affecting patterns of consumption. Traditional large retail units located outside cities and out of reach of public transport were thought to no longer be viable. Shopping centres in the future will likely not require owning and driving a car.

Every group highlighted the role of technology and art students as the creative class that appreciates technology on the one hand and sustainability on the other. Therefore, each group came up with ideas that support digitalization, alternative transport, alternative means of consumption, and diverse evening entertainment. Even the facades of the building were thought to represent sustainability and the technological identity, with wood and glass as the main material. The outcomes from the three groups' work are summarized below:

1. The first group wanted to focus on the offering, not on specific brands. Not unlike current shopping centres, large grocery stores open 24-hours per day would function as a basis, and other retailers would then follow. The group suggested restaurants and pubs that are open late at night for the creative class, and some facilities should be reserved for pop-ups. Additional services would include showrooms with warehouse pick-up locations for specialty stores. Ecological solutions in the design and services of the Metro Centre would define and strengthen the identity of the university. Ecology was even reflected in building design and emphasis was placed on building adaptability and an attractive façade. A hall for public lectures and other university events should be located centrally and be visible from the metro station entrance.

2. The second group also chose to focus on the offering, not on specific brands. It was clear that no specialty stores would be operated on campus, only supermarkets with good offerings. Restaurant services were thought to be best represented through a food court with "street food". The centre would also include art and entertainment, such as a gallery or a community centre. Some key concepts that were widely accepted within the group were fast, easy, entertainment, buzz, and flexible opening hours. As for the layout and structure of the centre, modularity and adaptability were marked as important. The building would boast a wooden façade to highlight the sustainability preferences of the creative class, and digitalized services in the centre would highlight the technology signature of the university. However, the new building should not undermine the architectural legacy of the university campus or the heritage of Alvar Aalto.

3. As with the other two groups, the third group also wanted to focus on the service offering, instead of specific brands. The student-customer segment brought about the suggestion of a discount supermarket to fit student budgets. Evening entertainment was also seen important for students, as were new digitalized services and other new types of services, such as sporting gear rental and a recycling service. A pop-up marketplace was also discussed. University and student services should be visible in the lobby, for example, in the form of an information desk and various course projects presented on walls. This group focused on accessibility and good visibility with a glass façade in their building design. City bikes and bike racks would be available to accommodate the students' most popular means of transport.

\section{Ruskeasuo Health Park}

This section presents the outcome of the second case, Ruskeasuo Health Park. Once again, the participants were not given any prerequisites regarding budget, layout, or types of services that would be welcomed to campus. The participants were provided with some basic information about the site and location but were asked to overlook any other physical constraints, such as the existing buildings on site.

The campus was envisioned as an accessible and inclusive community with lush green surroundings. A sense of community between the different organizations on campus was the driving force behind all three groups' work. Although the main user group was thought to be senior citizens, the groups were interested in making the campus easily accessible and attractive to other user groups as well. Accessibility was another key concept that was repeated in the outputs with regard to buildings and recreational activities. The role of the 


\section{The Cuckoo's Nest Approach for Co-Creating Business Ecosystems in Smart Cities} Karlos Artto, Riikka Kyrö, Tuomas Ahola, Antti Peltokorpi, and Kristiina Sandqvist

third sector, mainly different health associations, was also emphasized in providing a wide range of services beyond traditional public and private healthcare service providers.

Compared to the outcome of the Otaniemi Metro Centre, the Ruskeasuo Health Park workshop focused on the site, rather than a building. Therefore, building material choices were not discussed during the workshop. However, green roofs and walls were mentioned as a means to highlight the nature-friendly identity of the campus. Access to alternative transport, such as nearby bike routes and a bus line to the campus, was also seen as an important part of the new image of the Health Park. The campus is located adjacent to Helsinki's Central Park, and the park was included in all the group's outputs as a major source of recreation. Additionally, locally grown and organic food was discussed, and it was suggested that a community garden should be included in the design. The outcomes of the three group's work are summarized below:

1. Similar to the previous workshop, the first group wanted to focus on services, particularly the service offering of the whole campus, not of individual service providers. The group saw a strong sense of community as the guiding principle. Wellbeing is a sum of many parts, including recreation, dining, sports facilities, and culture. A number of third sector organizations would complement public health services. Hotel services for long-distance guests were also among the suggestions. Also, a "community feel beyond generations" could be achieved, it was suggested, by locating student dorm rooms inside a nursing home. This type of arrangement has been successfully implemented in the Netherlands and Finland before. The neighboring Central Park of Helsinki, with its nature and recreational opportunities, was seen as a major asset.

2. The second group wanted the campus to provide healthcare and experiences to the future customers. They saw senior citizens, children, health tourists, researchers, businesses, and local citizens as the key customer groups. The long cultural history of the campus was thought to be an attraction. This group also wished to see third sector organizations and smaller health technology startups in a central role. The environmental friendliness was depicted with a grocery store with organic food, and a restaurant serving harvest from an onsite rooftop garden. Additional green roofs and wall would further demon- strate green roofs, green walls to demonstrate environmental friendliness. The group also designed and accessible theme park or adventure park. The recreational activities should exploit the full potential of the nearby Central Park. Hotel services could be provided for long distance guests in a new building, and an event hall and information centre should be located centrally on the whole campus.

3. The third group saw community feel as the guiding principle of the new campus and wished to co-create a warm and welcoming to everyone. Both the local community and international health tourists were expected to belong to the future customer segment. The role of third sector organizations was deemed important in complementing public services, which may reflect both the context and high level of third sector participation in this workshop. The group wished to see a wide service offering including retail, pharmacy, spa, and cafes. Accessible recreational activities and sports halls were also among the design suggestions. As a niche offering, the group expressed interest in providing wellbeing services, including social services, mental health, and even spiritual guidance. Finally, the group thought that a new tramline running through campus might increase opportunities for passersby to discover the campus and its service offerings.

\section{Discussion}

Based on the feedback, everyone who took part in the workshops were extremely satisfied. In addition to cocreating innovative ideas, the workshops provided an opportunity to meet and talk with other potential future tenants, owners, and city officials. That way, even if the smart city project will not be relevant for their business in the future, they have opened communication channels with other businesses in the area.

Typically, co-design processes in the built environment have engaged a limited group of pre-determined users (e.g., Broberg et al., 2011), the design process has been led by a designer (e.g., Kyrö \& Artto, 2015), and efforts have focused on facility design (e.g., Kjolle \& Blakstad, 2014). These processes stand the risk of turning into a "barrel of wishes", where the lead designer tries to comply with the users' wishes only to the extent that it does not jeopardize the outcome desired by the owner of the project (e.g., a real estate developer or a city). The key difference in the Cuckoo's Nest approach to existing participatory methods is that the individuals are from a 


\section{The Cuckoo's Nest Approach for Co-Creating Business Ecosystems in Smart Cities} Karlos Artto, Riikka Kyrö, Tuomas Ahola, Antti Peltokorpi, and Kristiina Sandqvist

wider group of business representatives. It was clear from the very beginning that not all of the organizations would have tenancy on the campuses. Compared to the idea of service-dominant logic (Vargo \& Lusch, 2004), the included individuals were not the end customers. Furthermore, because the participants are all professional users, the outcome is different from that of a layman or citizen engagement group. The way that the complementing and competing organizations are brought together to ideate, with no direct benefit to their own organization, allows for the development of joint, system-level goal that benefits business as a whole. These two features make it more likely that the outcome is not about optimizing individual performance, but rather an optimal compilation with regard to the general understanding of what constitutes a functional business ecosystem.

As a result, the actor compilations were versatile, and smaller actors were well represented in the outcomes. For example, shopping centres in Finland typically host one or both of the two largest retail chains in the country, the national alcohol monopoly, and a Swedish clothing retailer, by default, and all other actors are fitted around these major players. Even though both of the largest retailers, as well as the national alcohol monopoly had their representatives at the Cuckoo's Nest workshop, none of the groups suggested this traditional compilation. This is not to say the final shopping centre will not host these major players; in all likelihood, it will. However, in the business ecosystem created in the workshop, the smaller actors had equal weight as the larger players, despite the existing power relations.

The strong focus on the technological identity of the Otaniemi campus and the unwillingness to place traditional shops in the shopping centre was made possible by the principles described above. Meanwhile, the diversity of workshop participants likely contributed to the focus on small pop-up services and startups in the Health Park workshop outcomes. Within the conservative field of healthcare, radical innovations tend to come from smaller actors outside the field.

\section{Conclusions}

Although neither of the two projects will be realized exactly as envisioned in the workshops, some ideas have translated into reality in the projects. The Otaniemi Metro Centre workshop participants met again one month later for a follow-up discussion. The research team presented the key outcomes of the workshop and future trends in shopping centres in general. The construction of the Otaniemi Metro Centre has started, and discussions with potential tenants are ongoing. For the Ruskeasuo Health Park case, the research team met with the owner and the owner's consultant after the workshop to discuss the outcomes. Inspired by the workshop, the Health Park now hosts third-party associations and small startups based on new health technologies.

Finally, based on the two Cuckoo's Nest workshop cases, it seems that when the individuals are given freedom and independence to ideate without any constraints, or without the need to directly benefit their own organization, they innately focus on the "common good". The end-result of the process is a value-creating business ecosystem, which has the capacity to create value even for decades, adapt to ever-changing context by renewing itself, and initiate new value-creating activities in the future. 


\section{The Cuckoo's Nest Approach for Co-Creating Business Ecosystems in Smart Cities}

Karlos Artto, Riikka Kyrö, Tuomas Ahola, Antti Peltokorpi, and Kristiina Sandqvist

\section{About the Authors}

Karlos Artto is a Professor and Lead of Project Business at Aalto University, Helsinki, Finland. Dr. Artto's long experience working in industry and the multiple research projects he conducted with global firms and domestic organizations provide a strong empirical basis for his academic achievements. His publications include more than 50 articles in refereed journals and more than 200 academic papers, book chapters, and books on project business and the management of project-based firms. He belongs to editorial boards of several project management journals. Dr. Artto has supervised 12 doctoral dissertations and more than 180 master's theses.

Riikka Kyrö is a Postdoctoral Researcher at Aalto University School of Science, Finland. Dr. Kyrö earned an M Sc in Real Estate Economics in 2005 from the Helsinki University of Technology and a DrSc (Tech) in Real Estate Business in 2013 from the Aalto University School of Engineering. Outside academia, she has six years of industry experience working with environmental consulting and sustainability in corporate real estate management. Dr. Kyrö has published nearly 30 academic articles in the field of the built environment.

Tuomas Ahola is an Assistant Professor in the Department of Industrial Management at the Tampere University of Technology, Finland, as well as an Adjunct Professor of Project Management at the Norwegian University of Science and Technology. Dr. Ahola specializes in inter-organizational networks in the context of project business. He has published more than 15 peer-reviewed journal articles. Dr. Ahola lectures on various content areas of project business for both academic and industry audiences.

Antti Peltokorpi is an Assistant Professor of Operations Management in Construction at Aalto University School of Engineering, Finland. Dr. Peltokorpi holds a DrSc (Tech) in Operations Management from the Aalto University School of Science. His research includes studies on service innovations, service production strategies, and production planning and control. Dr. Peltokorpi's research interests include value creation in business networks and supply chains, especially in the built environment, the construction industry, and healthcare.
Kristiina Sandqvist is a MA student in Collaborative and Industrial Design at Aalto University School of Arts, Design and Architecture in Finland. Ms. Sandqvist has industry experience as a service designer and is interested in the development and application of co-creation methods as well as the emerging roles of designers as facilitators.

\section{References}

Autio, E., \& Thomas, L. D. W. 2014. Innovation Ecosystems: Implications for Innovation Management. In M. Dodgson, D. M. Gann, \& N. Phillips (Eds.), The Oxford Handbook of Innovation Management: 204-228. Oxford: Oxford University Press. http://dx.doi.org/10.1093/oxfordhb/9780199694945.013.012

Booher, D. E., \& Innes, J. E. 2002. Network Power in Collaborative Planning. Journal of Planning Education and Research, 21(3): 221-236.

http://dx.doi.org/10.1177/0739456X0202100301

Bowen, S., McSeveny, K., Lockley, E., Wolstenholme, D., Cobb, M. \& Dearden, A. 2013. How Was It for You? Experiences of Participatory Design in the UK Health Service. CoDesign, 9(4): 230-246.

http://dx.doi.org/10.1080/15710882.2013.846384

Broberg, O., Andersen, V., \& Seim, R. 2011. Participatory Ergonomics in Design Processes: The Role of Boundary Objects. Applied Ergonomics, 42(3): 464-472.

http://dx.doi.org/10.1016/j.apergo.2010.09.006

Brown, M., \& Long, P. 2006. Trends in Learning Space Design. In D. G. Oblinger (Ed.), Learning Spaces: 9.1-9.11. Boulder, CO: Educause.

Casadesus-Masanell, R., \& Ricart, J. E. 2011. How to Design a Winning Business Model. Harvard Business Review, 89: 100-107.

Carmel-Gilfilen, C., \& Portillo, M. 2016. Designing With Empathy: Humanizing Narratives for Inspired Healthcare Experiences. HERD: Health Environments Research \& Design Journal, 9(2): 130-146.

http://dx.doi.org/10.1177/1937586715592633

Chesbrough, H. 2003. The Logic of Open Innovation: Managing Intellectual Property. California Management Review, 45(3): 33-58.

Chesbrough, H. 2007. Business Model Innovation: It's Not Just about Technology Anymore. Strategy \& Leadership, 35(6): 12-17. http://dx.doi.org/10.1108/10878570710833714

Elf, M., Eldh, A. C., Malmqvist, I., Öhrn, K., \& von Koch, L. 2016. Using of Group-Modeling in Predesign Phase of New Healthcare Environments: Stakeholder Experiences. HERD: Health Environments Research \& Design Journal, 9(2): 68-81. http://dx.doi.org/10.1177/1937586715599650

Forester, J. 1999. The Deliberative Practitioner: Encouraging Participatory Planning Processes. Cambridge, MA: MIT Press.

Hakanen, T., \& Jaakkola, E. 2012. Co-Creating Customer-Focused Solutions within Business Networks: A Service Perspective. Journal of Service Management, 23(4): 593-611.

http://dx.doi.org/10.1108/09564231211260431 


\section{The Cuckoo's Nest Approach for Co-Creating Business Ecosystems in Smart Cities} Karlos Artto, Riikka Kyrö, Tuomas Ahola, Antti Peltokorpi, and Kristiina Sandqvist

Horelli, L. (Ed.). 2013. New Approaches to Urban Planning - Insights from Participatory Communities. Helsinki: Aalto University.

Keysey, K. 1962. One Flew Over the Cuckoo's Nest. New York: Viking Press.

Kjolle, H. V., \& Blakstad, S. H. 2014. Architects and End Users: Boundary Objects in Participatory Briefing and Design. Nordisk arktekturforskning (Nordic Journal of Architecture), 26(1): 35-64.

Kyrö, R., Peltokorpi, A.m \& Artto, K. 2016. Engaging End-Users for Sustainable Repurposing and Improved Occupancy. In Proceedings of CIB World Building Congress WBC16, May 2016, Tampere, Finland.

Kyrö, R., \& Artto, K. 2015. The Development Path of an Academic Coworking Space on Campus - Case Energy Garage. Procedia Economics and Finance, 21: 431-438. http://dx.doi.org/10.1016/S2212-5671(15)00196-3

Luck, R. 2003. Dialogue in Participatory Design. Design Studies, 24(6): 523-535.

http://dx.doi.org/10.1016/S0142-694X(03)00040-1

Mäenpää, S., Suominen, A. H., \& Breite, R. 2016. Boundary Objects as Part of Knowledge Integration for Networked Innovation. Technology Innovation Management Review, 6(10): 25-36. https://timreview.ca/article/1025

Niemi, R., Rytkönen, E., Eriksson, R., \& Nenonen, S. 2015. Scaling Spatial Transformation: Smart Specialization of Urban Capabilities in the Helsinki Region. Technology Innovation Management Review, 5(10): 42-51. https://timreview.ca/article/936

Olson, M. 1965. The Logic of Collective Action: Public Goods and the Theory of Groups. Boston: Harvard University Press.
Ostrom, E. 1990. Governing the Commons: The Evolution of Institutions for Collective Action. Cambridge, UK: Cambridge University Press.

Perkins, N. H. 2013. Including Patients, Staff and Visitors in the Design of the Psychiatric Milieu: Notes from the Field. Facilities, 31(9/10): 379-390. http://dx.doi.org/10.1108/02632771311324945

Redström, J. 2006. Towards User Design? On the Shift from Object to User as the Subject of Design. Design Studies, 27(2): 123-139. http://dx.doi.org/10.1016/j.destud.2005.06.001

Ritala, P., Hurmelinna-Laukkanen, P., \& Nätti, S. 2012. Coordination in Innovation-Generating Business Networks-The Case of Finnish Mobile TV Development. Journal of Business \& Industrial Marketing, 27(4): 324-334. http://dx.doi.org/10.1108/08858621211221698

Rytkönen, E. 2015. University Campuses in Spatial Transformation: A Business Model Typology of Case Aalto University. Facilities, 33(13/14): 794-818. http://dx.doi.org/10.1108/F-04-2014-0042

Sanders, E. B. N., \& Stappers, P. J. 2008. Co-Creation and the New Landscape of Design. CoDesign: 41(1): 5-18. http://dx.doi.org/10.1080/15710880701875068

Sanoff, H. 2000. Community Participation Methods in Design and Planning. New York: John Wiley.

Vargo, S. L., \& Lusch, R., F. 2004. Evolving to a New Dominant Logic for Marketing. Journal of Marketing, 68(1): 1-17. http://dx.doi.org/10.1509/jmkg.68.1.1.24036

Citation: Artto, K., Kyrö, R., Ahola, T., Peltokorpi, A., \& Sandqvist, K. 2016. The Cuckoo's Nest Approach for Co-Creating Business Ecosystems in Smart Cities. Technology Innovation Management Review, 6(12): 26-37. http://timreview.ca/article/1039 